\title{
Erratum to: A new floating memristor emulator and its application in frequency-to-voltage conversion
}

\author{
Muhammad Taher Abuelma'atti ${ }^{1} \cdot$ Zainulabideen Jamal Khalifa $^{1}$
}

Published online: 16 December 2015

(C) Springer Science+Business Media New York 2015

\section{Erratum to: Analog Integr Circ Sig Process DOI 10.1007/s10470-015-0660-6}

Unfortunately, the second author's name was misspelled in the online version of this article. It is presented correctly in this erratum.

The online version of the original article can be found under doi: 10.1007/s10470-015-0660-6.

Muhammad Taher Abuelma'atti mtaher@kfupm.edu.sa

1 King Fahd University of Petroleum and Minerals, Box 203, Dhahran 31261, Saudi Arabia 